\title{
Synthesis and Characterization of Oxovanadium (Iv) Complexes and Metal (Ii) Schiff Base Complexes
}

\author{
SumanLal Shrestha \\ Department of Chemistry, Patan Multiple Campus, Tribhuvan University, Kathmandu, Nepal \\ *Corresponding Author: SumanLal Shrestha, Department of Chemistry, Patan Multiple Campus, \\ Tribhuvan University, Kathmandu, Nepal

\begin{abstract}
Sixteen symmetrical and four unsymmetrical tetradentate Schiff bases with the N2O2 chromophore were isolated in pure form and fully characterized by elemental analyses, melting point, IR. The appearance of two different peaks for each of the azomethine protons and phenolic protons confirm the asymmetry nature of the unsymmetrical Schiff bases. All the Schiff bases were successfully coordinated to oxovanadium (IV) ion to form the corresponding complexes. The unsymmetrical Schiff bases were also successfully coordinated to cobalt (II), nickel (II) and copper (II) ions to form their corresponding complexes. In all thirty-two metal (II) Schiff bases complexes were isolated. These complexes were characterized by elemental analyses, melting point, IR, EPR, cyclic voltammetry, magnetic susceptibility measurements, differential scanning calorimetry and electronic spectra.
\end{abstract}

Keywords: SchiffBases complexes, Vanadium(IV), Oxovanadium(IV).

\section{INTRODUCTION}

Schiff bases are typically formed by the condensation of a primary amine andan aldehyde/ketone. The resultant compound, $\mathrm{R}_{1} \mathrm{R}_{2} \mathrm{C}=\mathrm{NR}_{3}$, is called a Schiff base(named after Hugo Schiff), where $\mathrm{R}_{1}$ is an aryl group, $\mathrm{R}_{2}$ is a hydrogen atom and $\mathrm{R}_{3}$ is either an alkyl or aryl group. Schiff bases are generally bidentate $(\mathbf{1})$, tridentate $(\mathbf{2})$, tetradentate $(\mathbf{3})$ orpolydentate $(\mathbf{4})$ ligands capable of forming very stable complexes with transitionmetals. They can only act as coordinating ligands if they bear a functional group,usually the hydroxyl, sufficiently near the site of condensation in such a way that afive or six membered ring can be formed when reacting with a metal ion (Fig. 1.).<smiles>[R]N=C([R])c1ccccc1O</smiles>

Bidentate (1)

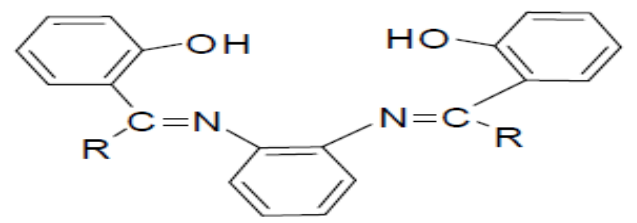

Tetradentate (3)<smiles>[R]C(=Nc1ccccc1C)c1ccccc1O</smiles><smiles>[Te]=CC=[Te]</smiles><smiles>[R]C(=Nc1ccccc1O)c1cc(C)cc(C([R])=Nc2ccccc2O)c1O</smiles>

Pentadentate

Figure1. Some classes of Schiff base ligands

Schiff bases play important roles in coordination chemistry as they easily formstable complexes with most transition metal ions [1,2]. In organic synthesis, Schiffbase reactions are useful in making carbon-nitrogen bonds.Complexes of $\mathrm{Ni}(\mathrm{II}), \mathrm{Co}(\mathrm{II})$ and $\mathrm{Cu}$ (II) with Schiff base ligands derived from 
$\beta$-diketones and $p$-anisidine have been reported [3]. Spectral and magnetic studies onthese complexes indicate that they are four coordinate, with square-planar geometry.It has been found that all the complexes are antimicrobially active and show higheractivity than the free ligands. Recently, there has been increasing interest in the synthes is andcharacterization of unsymmetrical Schiff base ligands and their metal complexes. This is due partly to the belief that the systematic investigation of these complexesmay shed light on the nature of complexes of biological interest [4]. Unsymmetri caltetradentate Schiff base complexes are required to model the irregular binding ofpeptides because trace metals have been found to occur in metalloenzymes boundto a macrocycle such as the heme ring, or to donor atoms of peptide chains usuallyin a distorted environment [5, 6]. Unsymmetrical ligands can clearly offer manyadvantages over their symmetrical counterparts in the elucidation of the compos itionand geometry of metal ion binding sites in metalloproteins and in the developmentleading to the duplication of enzymatic efficiency and selectivity of natural systemwith synthetic materials. A large percentage of enzymes have a metal atom at theactive site. These metalloenzymes facilitate a variety of reactions, which includeredox reaction (carried out by the oxidases and oxygenases), acidcatalysedhydrolysis (hydrolases) and rearrangement of carbon-carbon bonds (synthases andisomerases) $[7,8]$.

\section{EXPERIMENTAL}

\subsection{Mate rials}

All reagents and chemicals purchased from Aldrich-Sigma were ofanalytica1/spectroscopic grade and used without further purification. Chemicals andsolvents used for the preparation of Schiff base ligands and metal complexes are:salicylaldehyde, 5-chlorosalicylaldehyde, 5-nitrosalicylaldehyde,3ethoxysalicyla ldehyde,5-methoxysa licylaldehyde, 2-hydroxy-1-naphthaldehyde, ethylenediamine,1,2diaminopropane,1,3-diaminopropane, 2-hydroxybenzophenone, 1,2-phenylenediamine, oxovanadium (IV) sulphate hydrate, tetrabutylammoniumperchlorate, cobalt (II) acetate, nickel (II) acetate, copper (II) acetate, ethanol, methanol, triethylamine, chloroform, dimethsulphoxide, toluene, and dichloromethane.

\subsection{Synthesis}

\subsubsection{Preparation of Unsymmetrical Schiff Bases}

Ethanolic solutions of 2-hydroxy-1-naphthaldehyde (3.444 g, $20 \mathrm{mmol}), 1$,2-phenylenediamine $(2.163$ $\mathrm{g}, 20 \mathrm{mmol})$ and salicylaldehyde or substitutedsalicyla ldehyde $(20 \mathrm{mmol})$ in absolute ethanol $(75 \mathrm{~mL}$ each) were prepared andchilled in the refrigerator at $4^{\mathrm{oC}}$ for $15 \mathrm{~min}$. To a stirred solution of the cold 2hydroxy-1-naphthaldehyde, cold solution of 1,2-phenylenediamine was addeddropwise followed by the addition of cold solution of salicylaldehyde (or substitutedsalicylaldehyde) over a period of 2 min. The mixture was kept stirred at roomtemperature for 4 days, after which the mixture was warmed to, and kept at, $70^{\circ} \mathrm{C}$ for $20 \mathrm{~min}$ with stirring to dissolve any unreacted reactants and to complete thereaction. The product was filtered hot and washed twice with ice cold ethanol. Theorange product obtained was purified by digesting in hot ethanol, filtered hot, anddried in a desiccator over silica gel.

\subsubsection{Preparation of Symmetrical Schiff Bases}

The ligands were prepared according to established procedures [9]. Atypical procedure for the synthesis of the symmetrical Schiff base is as follows: To astirred solution of 0.08 mole of the appropriate 2-hydroxycarbonyl compound(aldehyde and ketone) in $60 \mathrm{~mL}$ absolute ethanol was added, drop wise, $0.04 \mathrm{~mol}$ ofan ethanolic solution of aliphatic or aromatic diamines. This mixture was then stirredfor $2 \mathrm{~h}$ at $50^{\circ \mathrm{C}}$. Afterwards the mixture was cooled to room temperature, or in ice, and the products formed were collected by filtration. The crystals were washed withcold absolute ethanol and re-crystallized from ethanol-chloroform $(1: 3 \mathrm{v} / \mathrm{v})$ mixture. The yellow crystals were dried in a desiccator over silica gel.

\subsubsection{Preparation of Oxovanadium(IV) Complexes}

The following general procedure was used in the synthesis of all theoxovanadiun(IV) complexes [10]. Oxovanadium(IV) sulphate (6 mmol, $0.978 \mathrm{~g}$ ) wasdissolved in hot absolute methanol $(300 \mathrm{~mL})$ and a mixture of triethylamine (12mmol, $1.214 \mathrm{~g}$ ) and the corresponding Schiff bases (6 mmol), dissolved in methanol $(20 \mathrm{~mL})$, was added with stirring, which resulted in an instant colour change togreen/orange. The mixture was stirred for $3 \mathrm{~h}$ at $50^{\circ \mathrm{C}}$ and then concentrated to halfof its volume 
using a rotary evaporator. The product was filtered and washed twicewith cold absolute ethanol and allowed to dry in a desiccator over silica gel.

\subsubsection{Preparation of the Cobalt(II), Nickel(II) and Copper(II) Complexes}

The various complexes were prepared by addition of $3 \mathrm{mmol}$ ofCo $\left(\mathrm{CH}_{3} \mathrm{COO}\right)_{2} \cdot 4 \mathrm{H}_{2} \mathrm{O}(0.53 \mathrm{~g})$, $\mathrm{Ni}\left(\mathrm{CH}_{3} \mathrm{COO}\right)_{2} \cdot 4 \mathrm{H}_{2} \mathrm{O}(0.75 \mathrm{~g})$ or $\mathrm{Cu}\left(\mathrm{CH}_{3} \mathrm{COO}\right)_{2} \cdot \mathrm{H}_{2} \mathrm{O}(0.60 \mathrm{~g})$ dissolved hot absolute methanol $(60 \mathrm{~mL})$ to a stirring $3 \mathrm{mmol}$ of therespective unsymmetrical Schiff bases in methanol (40 mL). The colour of themixture changed instantly. The mixture was refluxed for $3 \mathrm{~h}$ and the precipitatedsolids were filtered, washed with cold methanol and allowed to dry in a desiccatorover silica gel.

\subsection{Characterization of the Ligands and Complexes}

The ligands were characterized by elemental analysis, infrared and ${ }^{1} \mathrm{H}$ NMRwhile the metal complexes were characterized by elemental analyses, infrared, andelectronic spectral, cyclic voltammetry, electron paramagnetic resonance, and roomtemperature magnetic susceptibility measurements, and differential scanningcalorimetry.

\subsubsection{Microanalysis}

Carbon, hydrogen and nitrogen analysis was done on a Perkin-Elmer automated mode1 2400 Series II CHNS/O analyzer.

\subsubsection{Melting/Decomposition Points}

The melting/decomposition points were determined by placing afinely powered sample in a glass capillary and heating by usingBarnstead/electrothermal digital melting point apparatus and are uncorrected.

\subsubsection{Infrared Spectroscopy}

Infrared spectra were recorded on a spectrophotometer directly on small samples of the compounds in the range $200-4000 \mathrm{~cm}^{-1}$.

\subsubsection{Electronic Absorption Spectra}

Electronic absorption spectra in the UV-Visible region were recorded on aCary Model 50 spectrophotometer between 200-1100 nm in both chloroform andDMSO as solvents.

\subsubsection{Electron Paramagnetic Resonance (EPR)}

EPR spectra were measured using a EMX Micro Premium XSpectrometer at X-band $(9.4 \mathrm{GHz})$ on the powder and on the fluid and frozensolutions in toluene/dichloromethane $(90 / 10 \mathrm{v} / \mathrm{v})$.

\subsubsection{Magnetic Moments}

Magnetic susceptibility measurements done in house were made onpowdered samples using a Sherwood Scientific magnetic susceptibility balance. $\mathrm{Hg}\left[\mathrm{Co}(\mathrm{SCN})_{4}\right]$ was used as the calibrant and corrections for diamagnetism wereestimated from Pascal's constants.

\subsubsection{Cyclic Voltammetry}

The cyclic voltammetry on electrochemical detector. Glassycarbon electrode, platinum wire and $\mathrm{Ag} / \mathrm{Ag}^{+}$were used as working, supporting andreference electrodes respectively. Sample solutions were $10^{-3} \mathrm{M}$ of each complex inspectroscopic grade DMSO containing $0.1 \mathrm{M}$ tetrabutylammonium perchlorate as thesupporting electrolyte. Each solution was degassed with ultra pure $\mathrm{N}_{2}$ gas for 5 minbefore each measurement was made.

\subsubsection{Differential Scanning Calorimetry(DSC)}

Thermal analysis was carried on sample and reference pan are in separate furnaces heated by separateheaters. Both the sample and reference are maintained at the same temperatureand the difference in thermal power required to mainta in them at the sametemperature is measured and plotted as a function of temperature or time. Thedifferential heat flow is therefore only due to the heat capacity associated withheating the sample. Small samples $(5-10 \mathrm{mg})$ were weighed in an aluminium panand the mass noted. The pan was then covered with its cover, usually slightlysmaller. The pans are then crimped close using TA's Blue DSC sample press. Theenclosed sample was placed in the furnace 
side by side with the crimped closedempty aluminium pan as reference. The instrument is purged with ultra pure $\mathrm{N}_{2}$ gasat regulated pressure between 100 and $140 \mathrm{kPa}$ gauge (15 and $20 \mathrm{psig}$ ). The gasflow rate was set at $50 \mathrm{~mL}$ per min. Experiments were run from room temperature to500 ${ }^{\circ \mathrm{C}}$ at scan rates of $10^{\circ \mathrm{C}} / \mathrm{min}$.

\section{ReS ULTS AND Dis CUSSION}

A series of new structurally novel unsymmetrical Schiff base ligands wereprepared by the condensation reaction in a 1:1:1 molar ratio of 2-hydroxy-1-naphthaldehyde, o-phenylenediamine, and substituted salicylaldehyde orsalicylaldehyde and kept stirring at room temperature for four days. All ligandsformed were orange-yellow and melted at $134-195^{\circ} \mathrm{C}$. They were also obtained inhigh yield and in high purity. The procedure for the preparation of theunsymmetrical Schiff bases was developed in laboratory. The sequence ofreaction is shown as part of the Scheme presented in Figure 2. The followingfactors were found to affect the course of the synthesis: (i) the sequence of additionof the reagents, (ii) temperature of the solution of the starting reagents (solutionchilled to about $4^{\mathrm{oC}}$ ), (iii) the nature of the diamine (aliphatic or aromatic) used and(iv) the reaction time. A change of amine from o-phenylenediamine to 1,3-diaminopropane led to the formation of symmetrical Schiff base, N, N'bis(2-hydroxy-1-naphthalidene)-1, 3-diaminopropane, follow ing the same procedure. From theabove observation, it may be concluded that the resonance stabilization energy,arising from extended conjugation, reinforces the formation of the $o$-phen-bridgedSchiff base as against the symmetrical Schiff base formed with the aliphatic diamine.A change in reaction time from four days to just three hours or the use of warmsolutions of the starting reagents produced mixed products. From the aboveobservations, it seems that the condensation reactions occurred stepwise.

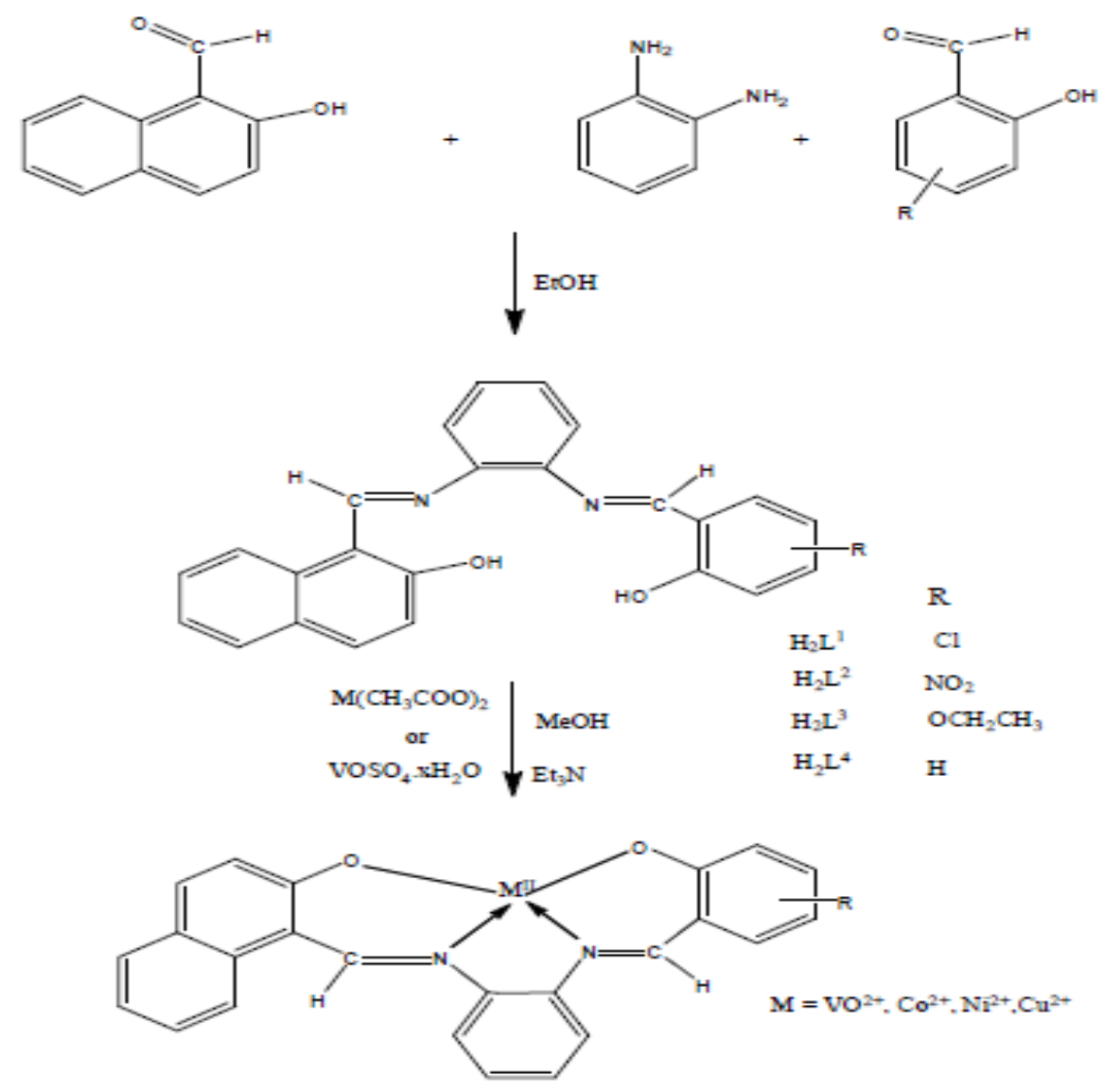

Figure2.Preparation of the unsymmetrical Schiff bases and their metal (II) complexes.

\section{Conclusions}

The involvement of azomethine $N$ and phenolic $O$ of the tertadentate Schiff bases to the metal ions was confirmed by comparing the IR data of the ligands with those of the metal(II) complexes. Further conclusive evidence of the coordination of these Schiff-bases with the metal ions was shown by the appearance of new bands due to $v(\mathrm{M}-\mathrm{N})$ and $v(\mathrm{M}-\mathrm{O})$ in the metal complexes. The unsymmetrical nature of the unsymmetrical Schiff bases and their metal(II) complexes was confirmed by the ir IR 
spectra where two bands were observed for each of $v(\mathrm{C}=\mathrm{N}), v(\mathrm{C}-\mathrm{O}), v(\mathrm{~V}-\mathrm{N})$ and $v(\mathrm{~V}-\mathrm{O})$, taking their origin from the different aldehydes contained in each ligand.

Most of the oxovanadium(IV) complexes exhibit a strong band in the range959-989 $\mathrm{cm}-1$, which have been assigned to $v(\mathrm{~V}=\mathrm{O})$ in a monomeric squarepyramidal environment. The oxovanadium(IV) complexes with trimethylene bridge, inwhich the $v(\mathrm{~V}=\mathrm{O})$ appeared at $848-860 \mathrm{~cm}-1$, have been assigned polymericstructure with $\cdots \cdot \mathrm{V}=\mathrm{O} \cdots \mathrm{V}=\mathrm{O} \cdots$ interactions, which afforded distorted octahedralcoordination geometry.The electronic spectral and magnetic susceptibility measurements were usedfor assigning the stereochemistry of each metal(II) complexes. For four-coordinatemetal(II) complexes, either a square planar or a tetrahedral configuration is possible. On the basis of electronic spectra, together with the magnetic moments, it waspossible for us to assign the preffered configuration for the metal(II) complexesreported herein. The electronic spectra indicate a low spin square-planar geometry for all thecobalt(II) complexes. This was also corroborated by the effective magnetic moment ofthe complexes, which lie in the range of 2.23-2.61 B.M., corresponding to oneunpaired electron for low spin square-planar cobalt(II) complexes. The appearance of a single $d-d$ transition in DMSO is attributed to solvent effect, indicating the possibilityof formation of five- or six-coordinate species.

\section{REFERENCES}

[1] J. Hine, C.Y. Yeh, Equilibrium in formation and conformational isomerization of imines derived from is obutyraldehyde and saturated aliphatic primary amines, J. Am. Chem. Soc. 89 (1967) 2669.

[2] R.J. Fessenden, J.S. Fessenden, Organic Chemistry, Brooks/Cole Publishing Company, USA, 1998.

[3] Z. Cimerman, S. Miljanic, N. Galic, Schiff bases derived from aminopyridines as spectrofluorimetric analytical reagents, CroaticaChemicaActa 73 (1) (2000) 81.

[4] A. Elmali, M. Kabak, Y. Elerman, Conformational study and structure of bis-N,N'-p-bromosalicylideneamine-1,2-diaminobenzene, J. Mol. Struct. 477 (2000) 151.

[5] M. Valcarcel, M.D. Laque de Castro, Flow-throgh Biochemical Sensors,Elsevier, Amsterdam., 1994.

[6] U. Spichiger-Keller, Chemical Sesors and Biosensors for Medical andBiological Applications, WileyVCH, Weinheim, 1998.

[7] J.F. Lawrence, R.W. Frei, Chemical Derivatization in Chromatography,Elsevier, Amsterdam, 1976.

[8] S. Patai (Ed.), the Chemistry of the Carbon-Nitrogen Double Bond, J. Wiley \&Sons, London, 1970.

[9] G.A. Kolawole, K.S. Patel, The stereochemistry of Oxovanadium(IV)Complexes derived from Salicylaldehyde and Polymethylenediamines, J. Chem.Soc. (Dalton Trans.) (1981) 1241.

[10] K.S. Patel, G.A. Kolawole, A. Earnshaw, Spectroscopic and MagneticProperties of Sch iff base Co mp le xes of Oxovanadium(IV) Derived from 3-methoxysalicylaldehyde and Aliphatic Diamines, J. Inorg. Nucl. Chem. 43 (1981)3107.

Citation: SumanLal Shrestha, "Synthesis and Characterization of Oxovanadium (Iv) Complexes and Metal (Ii) Schiff Base Complexes", International Journal of Advanced Research in Chemical Science (IJARCS), vol. 5, no. 4, pp. 10-14,2018. http://dx.doi.org/10.20431/2349-0403.0504003

Copy right: (C) 2018 Authors. This is an open-access article distributed under the terms of the Creative Commons Attribution License, which permits unrestricted use, distribution, and reproduction in any medium, provided the original author and source are credited. 